\title{
Effects of Endothelium-Derived Nitric Oxide on Renal Hemodynamics and Function in the Sheep Fetus
}

\author{
GUY A. BOGAERT, BARRY A. KOGAN, AND ROBERT A. MEVORACH
}

Department of Urology, University of California School of Medicine, San Francisco, California 94143-0738

\begin{abstract}
We investigated the effects of the endothelium-derived nitric oxide system on renal hemodynamics and function during the 3rd trimester in a chronically catheterized fetal sheep preparation. Acetylcholine caused a significant decrease in renal vascular resistance $(60 \%$ of the baseline value) as compared with aortic constriction (142\% of the baseline value). The effects of acetylcholine could be blocked by prior administration of $\mathrm{N}^{\omega}$-nitro-Larginine (renal vascular resistance $=102 \%$ of baseline) Sodium nitroprusside also caused a significant drop in renal vascular resistance (63\% of baseline), but this could not be blocked by $\mathrm{N}^{\omega}$-nitro-L-arginine ( $77 \%$ of baseline). Infusion of $\mathrm{N}^{\omega}$-nitro-L-arginine with blood pressure maintained at a constant level resulted in a significant increase in renal vascular resistance (148\% of the baseline value) as compared with saline alone ( $94 \%$ of baseline). Glomerular filtration rate increased after saline infusion $(156 \%$ of the baseline value), but this increase was blocked by $\mathrm{N}^{\omega}$-nitroL-arginine (87\% of baseline). Sodium excretion also increased $(340 \%)$, and this increase was blunted by $\mathrm{N}^{\omega}$-nitroL-arginine $(235 \%)$. We conclude that basal production of endothelium-derived nitric oxide results in ongoing renal vasodilation in 3rd-trimester fetal sheep, maintaining baseline renal blood flow. The endothelium-derived nitric oxide system can also be stimulated to an increased level of activity, and its blockade partially prevents the homeostatic response of the fetus to volume and salt overload. (Pediatr Res 34: 755-761, 1993)
\end{abstract}

\section{Abbreviations}

NO, endothelium-derived nitric oxide GFR, glomerular filtration rate

EDRF, endothelium-derived relaxing factor

Knowledge of the physiology of fetal renal hemodynamics and function is essential for the development of antenatal treatments of obstructive uropathy. Since Leonardo da Vinci at the beginning of the 16th century recorded his observation that the human fetus produces urine in utero [quoted by Needham (1)], there have been increasingly complex investigations of fetal renal physiology. Most have been in the ovine fetus-a well-accepted model $(2,3)$. Fetal renal blood flow is lower than postnatal values and increases only slightly with fetal age (4-6). Mean arterial blood pressure also increases slightly during gestation; thus, renal

Received March 22, 1993; accepted July 20, 1993

Correspondence and reprint requests: Barry A. Kogan, M.D., Department of Urology, U.575, University of California, San Francisco, CA 94143-0738.

Supported in part by Grant SROIDK43687-02 from the National Institutes of Health and the Feodor Lynen Stipend from the Alexander von Humboldt-Stiftung. Germany. vascular resistance, which is relatively high, remains constant during the 3 rd trimester $(4,5)$. The renin-angiotensin system, arginine vasopressin, and prostaglandins all have been shown to have a role in the control of fetal renal blood flow (7). The importance of NO on fetal renal blood flow has not been investigated.

Filtration fraction and GFR are low during fetal life, but both increase steadily during the 3rd trimester $(8,9)$. Because the increase in GFR parallels the increase in renal and body weight, the GFR/renal or body weight ratio is virtually constant $(8,10)$. The factors modulating filtration fraction and GFR in the fetus are complex and not well known, although the GFR increase is accounted for in part by increases in the surface area for filtration and the effective filtration pressure (partly a function of increased blood pressure) (11). Alterations in these parameters in the fetus caused by NO are unknown.

Renal tubular function, as evidenced by sodium chloride metabolism, has been studied extensively. Fractional excretion of sodium decreases from $11 \%$ to $5 \%$ during the 3rd trimester (9). Multiple factors play a role in this shift: renal tubular maturation $(9,12,13)$, relatively large amounts of extracellular fluid (14), the presence of circulating natriuretic factor (15), relative tubular insensitivity to circulating aldosterone (16), prostaglandins (17), the renal kallikrein-kinin system (18), and renal oxygen consumption (19). The proximal tubule participates to a lesser extent in reabsorbing the filtered sodium load. Therefore, a greater proportion of sodium is reabsorbed distally and the distal nephron, under physiologic conditions, plays an important role in glomerulo-tubular balance (20). The effects of NO on sodium excretion in the fetus are unknown.

Furchgott and Zawadzki (21) first demonstrated in 1980 that the vascular relaxation induced by the muscarinic agent acetylcholine was dependent on the presence of a functionally intact endothelium and postulated the release by endothelial cells of a labile humoral factor termed EDRF. Since that study, a variety of agonists have been shown to induce release of EDRF from endothelium of various vascular beds. Comparative pharmacologic studies and direct measurement have provided evidence that EDRF activity results from the release by endothelial cells of NO (22-24). Palmer et al. (25) have demonstrated that NO, which is synthesized by endothelial cells, originates from the terminal guanidine nitrogen atom of the amino acid L-arginine. There is evidence that a soluble enzyme is involved in this step, and this enzyme can be inhibited by several L-arginine analogues, $\mathrm{N}^{\mathrm{G}}$-monomethyl-L-arginine $(26,27)$ and $\mathrm{N}^{\omega}$-nitro-L-arginine (28). This inhibition is competitive and can be abolished by administration of $\mathrm{L}$-arginine $(27,28)$. Based on these interactions, increasing evidence in a wide range of organ systems points to the NO system as a major determinant of vascular tone, both in the resting state and in response to various stimuli (29).

The purpose of the present investigation was to study the role and importance of the renal vascular endothelium in the renal hemodynamics and function of the fetus. Chronically catheter- 
ized fetal sheep underwent infusions of an endothelium-dependent vasodilator (acetylcholine), an endothelium-independent vasodilator (sodium nitroprusside), and an NO inhibitor ( $\mathrm{N}^{\omega}$ nitro-L-arginine) to determine the effects on renal vascular resistance, GFR, and sodium excretion. We hypothesized that the NO system would play a role in baseline fetal renal hemodynamics and function because of the numerous reports of its activity in the mature kidney (30-32).

\section{MATERIALS AND METHODS}

Surgical preparation. Pregnant ewes carrying fetuses of $115 \mathrm{~d}$ gestation were premedicated with $400 \mathrm{mg}$ ketamine (Ketaset, ketamine $\mathrm{HCl}$, USP, Aveco, Fort Dodge, IA) intramuscularly. Surgical anesthesia consisted of $4 \mathrm{~mL}$ of epidural tetracaine hydrochloride (Pontocaine $\mathrm{HCl}$, Breon Laboratories, New York, NY) and s.c. lidocaine hydrochloride (Lidocaine 2\%, USP, Elkins-Sinn, Inc., Cherry Hill, NJ) for all maternal (1\%) and fetal $(0.2 \%)$ skin incisions. In addition, ketamine ( $50 \mathrm{mg}$ i.v.) was given every $10-15 \mathrm{~min}$ as necessary to maintain adequate maternal and fetal sedation (maternal ketamine crosses the placenta).

With strictly aseptic technique, a midline incision was made in the ventral abdomen of the ewe and the pregnant horn of the uterus exposed. A $10-\mathrm{cm}$ incision was made in the uterus directly over the hind portion of the fetus. One fetal hind limb was brought through the incision, and polyvinyl catheters (inner diameter $0.8 \mathrm{~mm}$; outer diameter $1.2 \mathrm{~mm}$ ) were inserted into the fetal dorsalis pedis artery and vein and passed centrally to locate the tip in the fetal descending aorta and inferior vena cava, respectively. The lower portion of the fetus was then exposed and, through a midline abdominal incision just below the umbilical cord, the urachus was ligated several centimeters distal to the bladder. A cuffed silicone catheter $(8 \mathrm{~F})$ was placed through the urachus into the bladder and secured with the proximal urachus tightly sealed around it. The urethra was then ligated so that the entire fetal urine output drained through the urachal catheter. (In males, this was accomplished by ligating the penile urethra; in females, a second incision was made above the symphysis pubis and the proximal urethra ligated.) The abdominal wall was closed anatomically. The fetus was then turned laterally and, through a left paravertebral incision, the aorta and the left renal vessels were exposed. The suprarenal aorta was dissected circumferentially and a handmade silicone constrictor placed around it. (This is designed to allow both free flow and graded degrees of vascular obstruction.) A portion of the left renal artery was dissected and an ultrasonic flow transducer (Perivascular Volume Flowsensor, 2R-Series, Transonic Systems, Ithaca, NY) secured around it. The incision was closed anatomically and the fetus replaced in the uterus, which was then closed in a watertight manner. All fetal catheters and two amniotic cavity catheters (one placed to monitor intrauterine pressure and the second to be connected with the fetal urachal catheter) were brought out through the uterus and the ewe's flank and protected by a cloth pouch sewn to the skin. The vascular catheters were filled with heparinized saline and plugged, and the free end of the bladder catheter was connected directly to one amniotic cavity catheter with a 16-gauge connector to ensure free drainage of the urine into the amniotic cavity. The maternal incision was closed in layers and $100 \mathrm{mg}$ of gentamicin (Gentocin, Schering Corporation USA, Kenilworth, NJ) and 1 million $U$ of penicillin (Penicillin G Potassium, USP, Bristol-Meyers Squibb, Princeton, $\mathrm{NJ})$ were administered into the maternal venous circulation and amniotic cavity on the day of the surgery and daily for $5 \mathrm{~d}$.

All protocols were approved by our institution's Committee on Animal Research.

Drug preparation. Acetylcholine chloride (Miochol, Iolab, Claremont, CA) was diluted in $0.9 \%$ saline at a concentration of $10 \mu \mathrm{g} / 10^{-3} \mathrm{~L}$. Sodium nitroprusside (Abbott Laboratories, Chicago, IL) was diluted in $5 \%$ dextrose solution at a concentration of $12.5 \mu \mathrm{g} / 10^{-3} \mathrm{~L}$. $\mathrm{N}^{\omega}$-nitro-L-arginine (Sigma Chemical Co., St. Louis, MO) was suspended at a $3-\mathrm{mg} / 10^{-3} \mathrm{~L}$ concentration in $0.9 \%$ normal saline. All solutions were prepared on the day of study.

General study techniques. Physiologic studies were begun no sooner than $48-72 \mathrm{~h}$ postoperatively. During the studies, the status of the fetus was checked before and after each drug application with arterial blood gas and lactate measurements. The ewe had constant access to food and water. One-h fetal urine collections were obtained with the intravesical pressure equal to the amniotic pressure, and a 3- to $5-\mathrm{mL}\left(10^{-3} \mathrm{~L}\right)$ sample was frozen immediately after collection (at $-18^{\circ} \mathrm{C}$ for a maximum of $10 \mathrm{~d}$ ). Serum from an arterial blood sample obtained $30 \mathrm{~min}$ after the beginning of the urine collection was also frozen at $-18^{\circ} \mathrm{C}$ (for a maximum of $10 \mathrm{~d}$ ). Sodium and creatinine concentrations of the urine and serum were determined with a Cobas Mira Chemistry Analyzer Ion Selective Electrode (Roche Diagnostic Systems, Nutley, NJ).

During the study, continuous measurements of blood pressure in the descending aorta and inferior vena cava and pressure in the amniotic cavity and fetal bladder were recorded on a Gould recorder (Gould 2800S, Gould Inc., Cleveland, $\mathrm{OH}$ ). Renal blood flow was monitored continuously, with the flow transducer read by the T101D/T201D Animal Research Flowmeter (Transonic Systems) connected to the Gould recorder.

Specific study methods. To determine whether NO could be stimulated to act on the renal circulation, baseline measurements of mean systemic arterial pressure (in the infrarenal aorta), inferior vena cava pressure, amniotic cavity pressure, and left renal blood flow were obtained. With continuous monitoring of the above parameters, three separate interventions were performed in random order: 1 ) i.v. infusion into the fetal inferior vena cava of acetylcholine $(0.5 \mu \mathrm{g} / \mathrm{kg} / \mathrm{min}) ; 2)$ i.v. infusion of sodium nitroprusside ( $2 \mu \mathrm{g} / \mathrm{kg} / \mathrm{min})$; and 3$)$ gradual constriction of the suprarenal aorta. The constriction was performed manually to reproduce the rate and amount of decrease in blood pressure caused by acetylcholine and sodium nitroprusside. The constriction and infusions were stopped when the blood pressure had decreased $10 \mathrm{~mm} \mathrm{Hg}$. The acetylcholine, nitroprusside infusions, and constriction were repeated after infusion of $\mathrm{N}^{\omega}$ nitro-L-arginine $(1.5 \mathrm{mg} / \mathrm{kg} / \mathrm{min})$. The acetylcholine infusion was continued for at least $10 \mathrm{~min}$ when no change in mean arterial pressure was observed; nitroprusside was continued until mean arterial pressure decreased $10 \mathrm{~mm} \mathrm{Hg}$.

To determine whether NO activity was ongoing, baseline measurements were made at least $30 \mathrm{~min}$ after any previous manipulation. With continuous monitoring of hemodynamic parameters as above, $\mathrm{N}^{\omega}$-nitro-L-arginine $(1.5 \mathrm{mg} / \mathrm{kg} / \mathrm{min})$ was infused into the fetal inferior vena cava. [ $\mathrm{N}^{\omega}$-nitro-L-arginine has been shown to be a competitive inhibitor of NO synthesis. The dosage used in this study has been previously reported to inhibit NO synthesis completely (33). This was confirmed by the failure of acetylcholine to induce hypotension in our study and others (34)]. During the infusion, the mean systemic arterial pressure in the lower aorta was kept constant by gradually constricting the suprarenal aorta.

To assess any effect of NO blockade on renal function, a 1-h urine collection was obtained after at least $1 \mathrm{~h}$ of continuous infusion for determination of volume, creatinine, and sodium. A blood sample to determine serum creatinine and sodium concentrations was obtained after $30 \mathrm{~min}$ of the urine collection. The following day, all parameters were remeasured and, after an infusion of acetylcholine (repeated to ensure complete elimination of $\mathrm{N}^{\omega}$-nitro-L-arginine), an infusion of $0.9 \%$ normal saline was begun at the same rate as the $\mathrm{N}^{\omega}$-nitro-L-arginine. Urine and blood samples were obtained at the same time points as after $\mathrm{N}^{\omega}$ nitro-L-arginine.

Measurements. Mean arterial pressure $(\mathrm{mm} \mathrm{Hg})$ was calculated by subtracting amniotic pressure from lower aortic pressure. Renal vascular resistance (expressed as $\mathrm{mm} \mathrm{Hg} \cdot \mathrm{kg} \cdot \mathrm{min} \cdot \mathrm{mL}^{-1}$ ) 
was calculated as follows: (mean arterial pressure - inferior vena cava pressure)/[(left renal blood flow.2)/fetal body weight]. In practice, vasodilation caused by acetylcholine and sodium nitroprusside resulted in an initial increase in renal blood flow; however, after further vasodilation with steadily decreasing mean arterial pressure, renal blood flow decreased (Fig. 1). The calculated renal vascular resistance would therefore vary with respect to the time point used to determine it. We thus chose to standardize the calculation of the renal vascular resistance by determining it throughout the study at the time when the mean arterial blood pressure had decreased from baseline values by precisely $10 \mathrm{~mm} \mathrm{Hg}$.

In fetal sheep, the creatinine clearance is virtually identical with $\mathrm{Na}$-iothalamate or inulin clearance $(35,36)$ and therefore the GFR (expressed as $\mathrm{mL} \cdot \mathrm{min}^{-1} \cdot \mathrm{kg}^{-1}$ ) was calculated as follows: (urinary output $\cdot$ urinary creatinine concentration)/(plasma creatinine concentration - fetal body weight). Filtration fraction $(\%)$ was calculated by dividing the GFR by twice the left renal blood flow. Sodium excretion (expressed as $\mathrm{mmol} \cdot \mathrm{h}^{-1} \cdot \mathrm{kg}^{-1}$ ) was calculated as follows: (urinary sodium concentration-urinary output)/fetal body weight. Fractional sodium excretion (\%) was calculated as follows: (urinary sodium concentration -serum creatinine concentration)/(serum sodium concentration -urinary creatinine concentration).

Statistical analysis. Baseline values for mean arterial pressure, renal blood flow, and renal vascular resistance between each intervention were compared with repeated measures analysis of variance. The effects of acetylcholine, sodium nitroprusside, suprarenal aortic constriction, and $\mathrm{N}^{\omega}$-nitro-L-arginine on the above parameters were compared with their respective baseline values by paired $t$ test. Changes in mean arterial pressure, renal blood flow, renal vascular resistance, urine volume, GFR, filtration fraction, fractional excretion of sodium, and sodium excretion after infusion of $\mathrm{N}^{\omega}$-nitro-L-arginine and saline were also compared with their respective baseline values by paired $t$ test. To differentiate the effects of NO better, the changes in renal vascular resistance after acetylcholine were compared with those after constriction with the paired $t$ test, and the changes in mean arterial pressure, renal blood flow, renal vascular resistance, urine volume, GFR, filtration fraction, fractional excretion of sodium, and sodium excretion after $\mathrm{N}^{\omega}$-nitro-L-arginine were compared with those after saline, also by paired $t$ test.

All values are presented as mean \pm SD. $p$ values $<0.05$ were considered statistically significant.
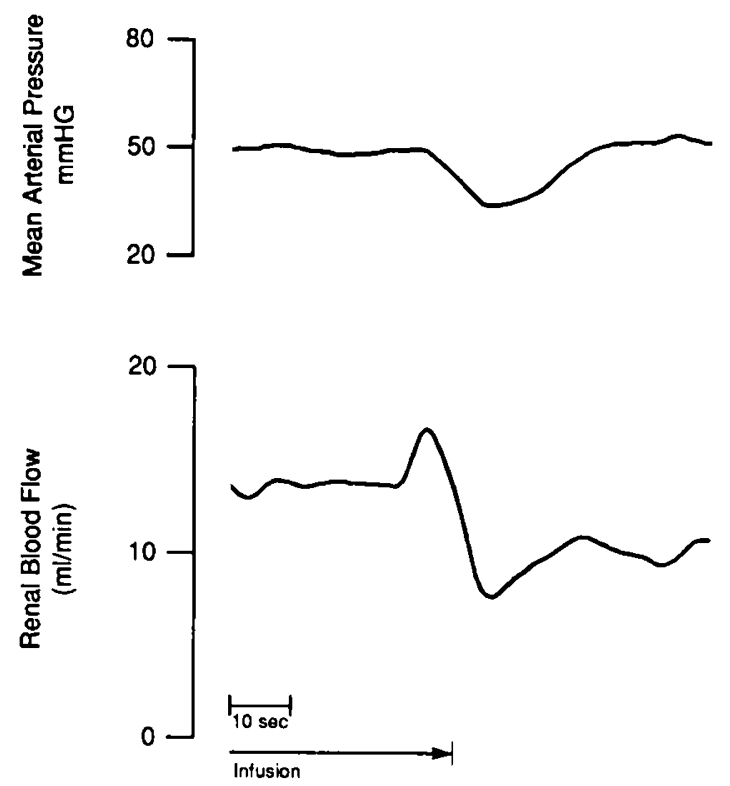

Fig. 1. Mean arterial pressure and renal blood flow during infusion of acetylcholine $(0.5 \mu \mathrm{g} / \mathrm{kg} / \mathrm{min})$.

\section{RESULTS}

All animals were healthy at the time of study, as determined by arterial blood gases and serum lactate (Table 1). Values did not change significantly during the study, except after $1 \mathrm{~h}$ of $\mathrm{N}^{\omega}$. nitro-L-arginine infusion with the suprarenal aorta constricted, after which there was mild oxygen desaturation and acidosis without change in serum lactate. The oxygen desaturation improved immediately upon releasing the constrictor, although the acidosis persisted. By the next day, the acidosis had resolved spontaneously. There were no significant differences in baseline hemodynamic parameters during the studies.

NO stimulation. Figures 1 and 2 depict tracings of the mean arterial pressure and the renal blood flow after acetylcholine and constriction of the suprarenal aorta, respectively. After infusion of acetylcholine, the renal blood flow slowly increased to a maximum, then decreased with steadily falling mean arterial pressure. Renal blood flow returned to baseline within $2 \mathrm{~min}$, although mean arterial pressure returned to normal within seconds. During aortic constriction (at a slow rate to reproduce the rate of decrease in systemic blood pressure), renal blood flow fell significantly immediately; however, after release of the constrictor a rebound effect was observed. As seen in Figure 3, acetylcholine significantly reduced renal vascular resistance as compared with use of the constrictor $(p<0.01)$. The changes induced by acetylcholine were blocked completely by infusion of $\mathrm{N}^{\omega}$. nitro-L-arginine (Table 2); similar changes seen after infusion of sodium nitroprusside were not altered by $\mathrm{N}^{\omega}$-nitro-L-arginine.

Baseline NO activity. Infusion of $\mathrm{N}^{\omega}$-nitro-L-arginine with blood pressure maintained constant resulted in significant reduction in renal blood flow $(p<0.005)$ (Table 3$)$ and an increase in renal vascular resistance $(p<0.002)$ (Fig. 4). Saline infusion resulted in a significant increase in renal blood flow, but the renal vascular resistance remained stable; the effect on both values was significantly more marked after $\mathrm{N}^{\omega}$-nitro-L-arginine $(p<0.001)$.

Renal function changes. Saline infusion resulted in an increase in urine volume $(p<0.03)$ and GFR $(p<0.02)$ and both fractional and total sodium excretion $(p<0.044$ and 0.008$)$ (Table 3). $\mathrm{N}^{\omega}$-nitro-L-arginine, given with saline infusion, blocked the increase in GFR $(p<0.047)$ and total sodium excretion $(p$ $<0.048$ ) but had no statistically significant effect on urine volume or fractional sodium excretion.

\section{DISCUSSION}

Infusion of $\mathrm{N}^{\omega}$-nitro-L-arginine in our chronic fetal sheep preparation resulted in a significant increase in mean arterial pressure. We therefore chose to constrict the suprarenal aorta during the infusion to maintain constant blood pressure in the renal circulation. With this preparation, we have demonstrated a definitive increase in renal vascular resistance during blockade of NO. This suggests ongoing basal NO secretion, which plays a role in regulating the baseline fetal renal vascular tone during the 3rd trimester. In addition, the decrease in renal vascular resistance after infusion of acetylcholine demonstrates that the NO system can be stimulated and may also influence renal vasodilation in the fetus.

Our findings are similar to the results of other investigators studying hemodynamics in the fully developed renal vasculature. Since 1988, numerous investigations with the isolated perfused rat kidney have shown that acetylcholine causes dose-related vasodilation. Inhibition of NO biosynthesis reduces or abolishes the response to acetylcholine without affecting vasodilation due to nitroprusside, an endothelium-independent vasodilator (34). This has been confirmed by several different investigators $(5,30$, 37-39). Micropuncture studies have also shown evidence that endothelial cells of the main renal artery modulate intrarenal hemodynamics and renal vascular resistance in the rat (39), and in vivo rodent studies have confirmed these observations $(40$, 41). Other chronic in vivo studies in a dog preparation have 
Table 1. Effects of NO blockade on fetal blood gas and lactate levels

\begin{tabular}{|c|c|c|c|c|c|c|c|}
\hline & $n$ & $\begin{array}{c}\mathrm{Hb} \\
\left(\mathrm{g} / 10^{-1} \mathrm{~L}\right) \\
\end{array}$ & $\begin{array}{c}\text { Oxygen } \\
\text { saturation } \\
(\%)\end{array}$ & $\mathrm{pH}$ & $\begin{array}{l}\mathrm{PCO}_{2} \\
(\mathrm{kPa})\end{array}$ & $\begin{array}{c}\mathrm{PO}_{2} \\
(\mathrm{kPa})\end{array}$ & $\begin{array}{c}\text { Lactate } \\
(\mathrm{mmol} / \mathrm{L})\end{array}$ \\
\hline Baseline & 8 & $9.5 \pm 2.0$ & $52.6 \pm 6.5$ & $7.38 \pm 0.01$ & $53.6 \pm 4.9$ & $20.7 \pm 2.6$ & $1.4 \pm 0.4$ \\
\hline $\begin{array}{l}\mathrm{N}^{\omega}{ }^{\omega} \text {-nitro-L-arginine and oc- } \\
\text { cluder }\end{array}$ & 8 & $9.9 \pm 1.7$ & $38.2 \pm 9.2$ & $7.29 \pm 0.02$ & $60.4 \pm 3.5$ & $19.3 \pm 2.7$ & $1.4 \pm 0.4$ \\
\hline $\mathrm{N}^{\omega}$-nitro-L-arginine & 8 & $10.6 \pm 2.2$ & $46.4 \pm 12.2$ & $7.30 \pm 0.02$ & $57.5 \pm 3.6$ & $22.0 \pm 3.9$ & $1.6 \pm 0.4$ \\
\hline $24 \mathrm{~h}$ after study & 8 & $9.6 \pm 1.7$ & $53.0 \pm 6.4$ & $7.38 \pm 0.02$ & $54.4 \pm 2.2$ & $20.9 \pm 2.2$ & $1.6 \pm 0.7$ \\
\hline
\end{tabular}

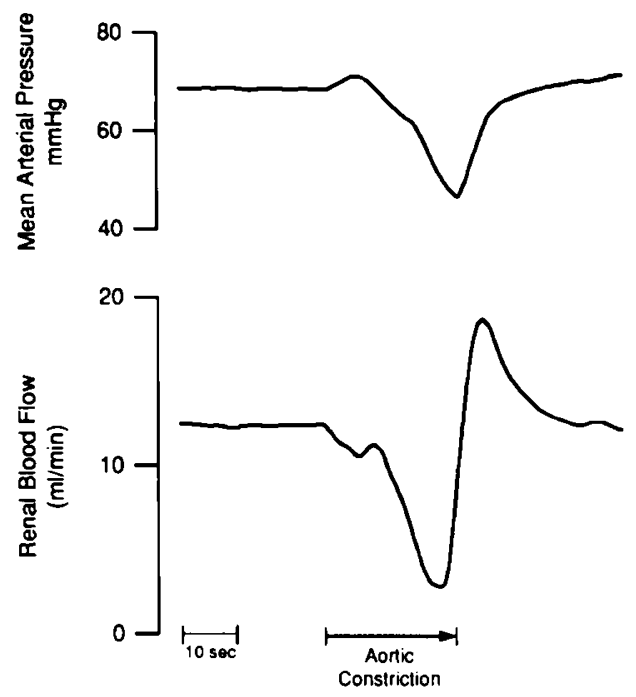

Fig. 2. Mean arterial pressure and renal blood flow in response to aortic constriction.

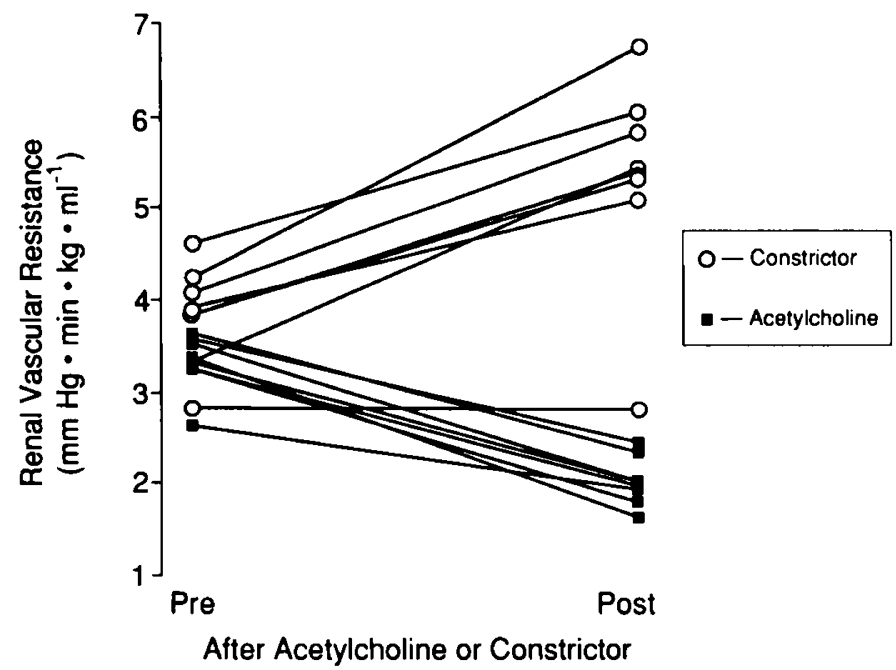

Fig. 3. Comparison of responses in renal vascular resistance to acetylcholine or constriction.

demonstrated hypertension and a rise in renal vascular resistance as a result of blockade of the NO system (31). Whether large or small vessels are involved is unclear from our study; however, a microangiographic study in isolated perfused rat kidneys demonstrated that the vasodilatory action of acetylcholine is spatially homogeneous (42).

Studies of the NO system in the fetus have been limited, most evaluating its role in pulmonary circulation. Almost 30 years ago, Cassin et al. (43) showed that acetylcholine dilates the normally high-tone pulmonary vasculature of the fetus. More recent studies have confirmed that the NO system can be stimulated with acetylcholine to modulate pulmonary blood flow in the near-term fetus (44) and that it affects both large and small pulmonary vessels (45). Studies have shown that stimulation or blockade of NO can have varying effects in different vessels, implying regional differences in vasodilator effects in the same animal (46). Thus, other organ systems are being studied.

In vitro studies by Shaul et al. (47) indicate that oxygen might also modulate NO production in fetal sheep pulmonary arteries. Within a normal physiologic range, this modulation is likely to be more prominent in the pulmonary circulation than in other organ systems. In the kidney, it has been shown that severe ischemia - with no flow to the kidney for $25 \mathrm{~min}$-results in an increase in renal vascular resistance (48). This is not comparable to the current study in which infusion of $\mathrm{N}^{\omega}$-nitro-L-arginine and constriction of the aorta led to statistically significant but relatively mild hypoxia. A recent study of mature kidneys in anesthetized dogs demonstrated that hypoxia (50\% of the baseline $\mathrm{PO}_{2}$ ) and NO inhibition both result in an increase of renal vascular resistance, although their effect in concert was not different from their effect individually (49). In our study, the change from the baseline $\mathrm{PO}_{2}$ induced by $\mathrm{NO}$ inhibition and aorta constriction was not statistically significant $(94 \%)$. This suggests that the results of NO inhibition seen in our study were not altered by the hypoxia.

Because acetylcholine infusion causes significant hypotension, it was not possible to evaluate the renal functional changes associated with acetylcholine stimulation of $\mathrm{NO}$ in our in vivo preparation. We therefore chose to use NO blockade with $\mathrm{N}^{\omega}$ nitro-L-arginine to determine whether inhibition of basal NO activity affects renal function. Although mean arterial pressure rose during $\mathrm{N}^{\omega}$-nitro-L-arginine infusion, we maintained renal arterial blood pressure at a constant level by constriction of the suprarenal aorta as necessary. Consequently, in our study (unlike other in vivo studies reported) renal vascular resistance and renal function could be determined independent of hypertension.

Our baseline GFR determination $\left(1.63 \pm 0.45 \mathrm{~mL} \cdot \mathrm{min}^{-1}\right.$. $\left.\mathrm{kg}^{-1}\right)$ was similar to that previously reported $(1.59 \pm 0.15 \mathrm{~mL}$. $\left.\mathrm{min}^{-1} \cdot \mathrm{kg}^{-1}\right)(50)$. In our preparation, a 2-h infusion of saline was necessary to study the effects of $\mathrm{N}^{\omega}$-nitro-L-arginine on GFR, resulting in a volume load of $60 \mathrm{~mL} / \mathrm{h}$ and $9.24 \mathrm{mmol} \mathrm{NaCl} / \mathrm{h}$. Thus, we used an infusion of $0.9 \%$ normal saline at $60 \mathrm{~mL} / \mathrm{h}$ (also $9.24 \mathrm{mmol} \mathrm{NaCl} / \mathrm{h}$ ) as a control. After saline infusion, GFR was increased, but this effect was abolished by $\mathrm{N}^{\omega}$-nitro-L-arginine.

Studies of the glomerular microcirculation of the rat kidney during blockade of the NO system demonstrated no change in single-nephron GFR (51). This results from several opposing factors, systemic hypertension and glomerular vasoconstriction and hypoperfusion; efferent resistance was disproportionately increased, resulting in elevated glomerular hydraulic pressure (51). In our study, filtration fraction was unchanged after $\mathrm{N}^{\omega}$ nitro-L-arginine, also suggesting that the NO blockade caused efferent arteriolar vasoconstriction, which maintained filtration despite decreased renal blood flow. The results of previous whole organ studies in mature animals are also generally supportive of our findings. In isolated perfused rat kidneys, stimulation of the NO system with acetylcholine resulted in a dose-dependent increase in GFR that could be blocked by infusion of an NO inhibitor or by arterial denudation by external rubbing of the main renal artery $(39,52)$. Similarly, an in vivo study in dogs undergoing local kidney perfusion with an NO inhibitor dem- 
Table 2. Effects of NO on renal vascular resistance*

\begin{tabular}{|c|c|c|c|c|c|c|}
\hline & $n$ & Acetylcholine & Constrictor & $\begin{array}{c}\text { Sodium } \\
\text { nitroprusside }\end{array}$ & $\begin{array}{l}\text { Acetylcholine after } \\
\mathrm{N}^{\omega} \text {-nitro-L-arginine }\end{array}$ & $\begin{array}{c}\text { Sodium } \\
\text { nitroprusside after } \\
\mathrm{N}^{\omega} \text {-nitro-L-arginine }\end{array}$ \\
\hline \multicolumn{7}{|c|}{ Mean arterial pressure $(\mathrm{mm} \mathrm{Hg})$} \\
\hline Pre & 8 & $41 \pm 4$ & $41 \pm 4$ & $42 \pm 4$ & $52 \pm 5$ & $50 \pm 6$ \\
\hline Post & 8 & $\begin{array}{r}33 \pm 6 \dagger \\
(80)\end{array}$ & $\begin{array}{r}32 \pm 4 \dagger \\
(78)\end{array}$ & $\begin{array}{r}32 \pm 4 \dagger \\
(76)\end{array}$ & $\begin{array}{l}50 \pm 5 \\
(96)\end{array}$ & $\begin{array}{c}41 \pm 6 \dagger \\
(82)\end{array}$ \\
\hline \multicolumn{7}{|c|}{ Renal blood flow $\left(\mathrm{mL} \cdot \mathrm{min}^{-1} \cdot \mathrm{kg}^{-1}\right)$} \\
\hline Pre & 8 & $12.4 \pm 2.2$ & $11.6 \pm 2.9$ & $11.1 \pm 2.0$ & $11.9 \pm 2.2$ & $11.9 \pm 2.4$ \\
\hline Post & 8 & $\begin{array}{c}16.3 \pm 3.4 \dagger \ddagger \\
(131)\end{array}$ & $\begin{array}{c}6.6 \pm 2.8 \dagger \ddagger \\
(57)\end{array}$ & $\begin{array}{l}12.9 \pm 1.8 \dagger \\
\quad(116)\end{array}$ & $\begin{array}{l}11.7 \pm 2.0 \\
\quad(98)\end{array}$ & $\begin{array}{l}12.3 \pm 2.1 \\
\quad(103)\end{array}$ \\
\hline \multicolumn{7}{|c|}{$\begin{array}{l}\text { Renal vascular resistance (mm Hg. } \\
\left.\min \cdot \mathrm{kg} \cdot \mathrm{mL}^{-1}\right)\end{array}$} \\
\hline Pre & 8 & $3.38 \pm 0.39$ & $3.87 \pm 0.66$ & $3.88 \pm 0.70$ & $4.36 \pm 0.93$ & $4.28 \pm 0.97$ \\
\hline Post & 8 & $\begin{array}{c}2.04 \pm 0.32 \dagger \ddagger \\
(60)\end{array}$ & $\begin{array}{c}5.34 \pm 1.36 \dagger \ddagger \\
(138) \\
\end{array}$ & $\begin{array}{c}2.51 \pm 0.31 \dagger \\
(65) \\
\end{array}$ & $\begin{array}{c}4.28 \pm 0.90 \\
(98)\end{array}$ & $\begin{array}{c}3.28 \pm 0.73 \dagger \\
(77)\end{array}$ \\
\hline
\end{tabular}

* Pre, baseline values; Post, after drug delivery. Numbers in parentheses are \% of baseline value.

+ Different from baseline, $p<0.05$.

$¥$ Change from baseline is different between acetylcholine and constrictor, $p<0.05$.

onstrated a significant decrease in GFR (53). However, another in vivo study in dogs demonstrated no change in GFR after blocking NO, although hypertension-an invariable response to significant blockade - was not controlled (31). The presence of hypertension might ameliorate the decrease in GFR seen in our study in which blood pressure was maintained at a constant level.

We used sodium excretion as a measure of renal tubular function. In ovine fetuses, both proximal and distal tubular sodium reabsorption is functional; however, the proximal tubule participates to a lesser extent than in mature kidneys, possibly because the fetus is in a relatively "volume-expanded" state or because the kidney is functionally immature (20). Our baseline values $\left(0.31 \pm 0.19 \mathrm{mmol} \cdot \mathrm{h}^{-1} \cdot \mathrm{kg}^{-1}\right)$ of sodium excretion are comparable to those previously reported for fetal lambs in sodium balance $\left(0.49 \pm 0.14 \mathrm{mmol} \cdot \mathrm{h}^{-1} \cdot \mathrm{kg}^{-1}\right)(54)$. After saline infusion, urine volume increased significantly, as did both fractional and total sodium excretion. A previous investigation has shown that, although the fetus loses more sodium via lung fluid than through renal excretion, the relationship between the latter and sodium intake is direct (54). Thus, an increase in sodium excretion would not have been surprising because our infusion rate $\left(4.62 \mathrm{mmol} \cdot \mathrm{h}^{-1} \cdot \mathrm{kg}^{-1}\right)$ was considerably greater than the normal sodium intake of a fetal lamb in sodium balance $(1.39 \pm$ $\left.0.17 \mathrm{mmol} \cdot \mathrm{h}^{-1} \cdot \mathrm{kg}^{-1}\right)(54)$.

Although urine volume and fractional excretion of sodium were not affected by $\mathrm{N}^{\omega}$-nitro-L-arginine, total sodium excretion was significantly reduced primarily because of a decrease in filtered sodium load. RIA to determine cGMP, an index of NO production of renal medulla and cortex in the dog kidney, showed the highest concentration in the medulla and a progressive decrease in concentration toward the cortex (55). This suggests a role for NO in the regulation of sodium reabsorption, although the evidence is not strong. Other in vivo studies of sodium excretion in mature kidneys are conflicting. A decrease in total sodium excretion after blockade of the NO system was seen in studies of local infusion of anesthetized dog kidneys (53), as well as in a long-term study with conscious dogs (31). However, the influence of local or systemic hypertension caused by the NO inhibitor was not excluded (31). In another study with anesthetized dogs in which NO blockade caused no hypertension but resulted in a decrease in renal blood flow and an increase in renal vascular resistance, sodium excretion did not change (56). However, stimulation of the NO system with acetylcholine, administered into the renal artery, in a different study (57) resulted in a $259 \%$ increase in sodium output. In our investigation, we were only able to study NO blockade, inasmuch as stimulation of the NO system resulted in a significant drop in systemic arterial pressure. Furthermore, our results with NO blockade may vary from those previously reported because we maintained constant blood pressure.

Why the NO system should be active in the last-trimester fetal kidney is unknown. Clearly, it helps to maintain baseline fetal homeostasis and may help regulate the fetal response to some pathologic processes. Studies in adult rats after bilateral ureteral obstruction have shown decreased availability of arginine for NO synthesis, suggesting that part of the renal ischemia noted after obstruction may be mediated by a lack of NO (58). It has also been shown that renal blood flow initially increases immediately after renal obstruction. This may be prostaglandin mediated, or NO may be involved. Additionally, the fetal kidney during the 3rd trimester responds to partial obstruction with a prolonged increase in renal blood flow, far longer than in postnatal studies (59). Perhaps activity of the nitric oxide/EDRF system accounts for this difference. Further investigation of its role in pathologic processes is essential.

Acknowledgments. The authors thank Drs. Michael Heymann, Julien Hoffman, and Jeffrey Fineman for assistance in study design, statistical analysis, and manuscript preparation and Paul Sumner and Christine Roman for technical assistance.

\section{REFERENCES}

1. Needham J 1963 Chemical Embryology, Vol 1. Hafner Publishing Co, New York, pp 107-110

2. Rudolph AM, Heymann MA 1985 Methods for studying the circulation of the fetus in utero. In: Nathanielsz PW (ed) Animal Models in Fetal Medicine (1). Perinatology Press, Ithaca, NY, pp 1-55

3. Alexander DP, Nixon DA, Widdas WS, Wohlzogen FX 1958 Renal function in the sheep foetus. J Physiol (Lond) 140:14-22

4. Aperia A, Broberger $O$, Herin P, Joelsson I 1977 Renal hemodynamics in the perinatal period. Acta Physiol Scand 99:261-269

5. Beguin F, Dunnihoo DR, Quilligan EJ 1974 Effect of carbon dioxide elevation on renal blood flow in the fetal lamb in utero. Am J Obstet Gynecol 119:630637

6. Robillard JE, Weismann DV, Herin P 1981 Ontogeny of single glomerular perfusion rate in fetal and newborn lambs. Pediatr Res 15:1248-1255

7. Robillard JE 1987 Development of function in fetal kidney. In: Holliday M, Barrett TM, Vernier RL (eds) Pediatric Nephrology, 2nd Ed. Williams \& Wilkins, Baltimore, pp 901-911

8. Robillard JE, Kulvinskas C, Sessions C, Burmeister L, Smith FGJ 1975 Maturational changes in the fetal glomerular filtration rate. Am J Obstet Gynecol 122:601-606

9. Robillard JE, Sessions C, Kennedey RL, Hamel-Robillard L, Smith FGJ 1977 Interrelationship between glomerular filtration rate and renal transport of sodium and chloride during fetal life. Am J Obstet Gynecol 128:727-734

10. Rankin JHG, Gresham EL, Battaglia FC, Makowski EL, Meschia G 1972 Measurement of fetal renal inulin clearance in a chronic sheep preparation. J Appl Physiol 32:129-133

11. Maddox DA, Brenner BM 1991 Glomerular ultrafiltration. In: Brenner BM, Rector FC (eds) The Kidney. WB Saunders, Philadelphia, pp 205-244

12. Fetterman GH, Shuplock NA, Philipp FI, Gregg HS 1965 The growth and 


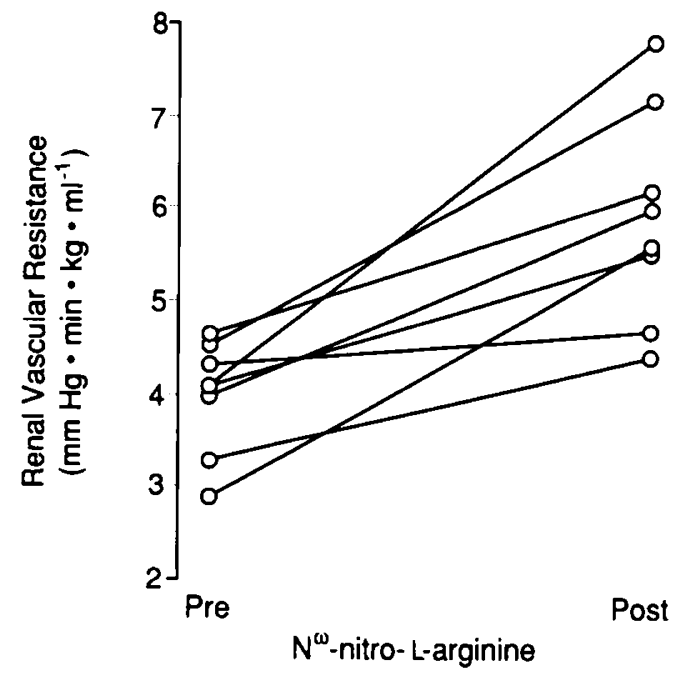

Fig. 4. Response of renal vascular resistance to infusion of $\mathrm{N}^{\omega}$-nitroL-arginine.

maturation of human glomeruli and proximal complications from term to adulthood: studies by microdissection. Pediatrics 35:601-619

13. McCance RA, Widdowson EM 1953 Renal function before birth. Proc R So Lond B Biol Sci 141:488-497

14. Robillard JE, Sessions C, Biermeister L, Smith FG 1977 Influence of fetal extracellular volume contraction in renal reabsorption of bicarbonate in fetal lambs. Pediatr Res 11:649-655

15. Hurley JK, Kirkpatrick SE, Pitlick PT, Friedman WF 1977 Renal responses of the fetal lamb to fetal or maternal volume expansion. Circ Res 40:557560

16. Sulyok E, Nemeth M, Tenyi F, Csaba IF, Varga L, Varga F 1982 Relationship between the postnatal development of the renin-angiotensin-aldosterone system and electrolyte and acid-base status of the $\mathrm{NaCl}$-supplemented premature infants. In: Spitzer A (ed) The Kidney During Development: Morphology and Function. Mason, New York, pp 273-281

17. Dunn MJ 1979 Renal prostaglandins: influences on excretion of sodium and water, the renin angiotensin system, renal blood flow, and hypertension. In: Brenner BMA, Stern JH (eds) Hormonal Function and the Kidney. Churchill Livingstone, New York, pp 89-114

18. Carretero DA, Scicli AG 1980 The renal kallikrein-kinin system. Am J Physio 238:F247-F255

19. Elinder G, Aperia A 1982 Renal oxygen consumption and sodium reabsorption during isotonic volume expansion in the developing rat. Pediatr Res 16:351353

20. Lumbers ER, Hill KJ, Bennett VJ 1988 Proximal and distal tubular activity in chronically catheterized fetal sheep compared with the adult. Can J Physiol Pharmacol 66:697-702

21. Furchgott RF, Zawadzki JV 1980 The obligatory role of endothelial cells in the relaxation of arterial smooth muscle by acetylcholine. Nature 288:373376

22. Ignarro LJ, Byrns RE, Wood KS 1988 Biochemical and pharmacological properties of endothelium-derived relaxing factor and its similarity to nitric oxide radical. In: Vanhoutte PM (ed) Vasodilation: Vascular Smooth Muscle, Peptides, Autonomic Nerves, and Endothelium. Raven Press, New York, pp 427-436

23. Hutchinson PJA, Palmer RMJ, Moncada S 1987 Comparative pharmacology of EDRF and nitric oxide on vascular strips. Eur J Pharmacol 141:145-15

24. Palmer RMJ, Ferrige AG, Moncada SL 1987 Nitric oxide release accounts for the biological activity of endothelium-derived relaxing factor. Nature 327:524-526

25. Palmer RMJ, Ashton DS, Moncada S 1988 Vascular endothelial cells synthetize nitric oxide from L-arginine. Nature 333:664-666

26. Palmer RMJ, Rees DD, Ashton DS, Moncada S 1988 L-Arginine is the physiological precursor for the formation of nitric oxide in endotheliumdependent relaxation. Biochem Biophys Res Commun 153:1251-1256

27. Rees DD, Palmer RMJ, Hodson HF, Moncada S 1989 A specific inhibition of nitric oxide formation from L-arginine alternates endothelium-dependent relaxation. Br J Pharmacol 96:418-424

28. Ishii K, Chang B, Kerwin YFJ, Huang Z, Murad F $1990 \mathrm{~N}^{\omega}$-nitro-L-arginine: a potent inhibitor of endothelium-derived relaxing factor formation. Eur $\mathrm{J}$ Pharmacol 176:219-223

29. Moncada S 1990 The First Robert Furchgott Lecture: from endotheliumdependent relaxation to the L-arginine: NO pathway. Blood Vessels 27:208217

30. Rademacher J, Forstermann U, Frölich C 1990 Endothelium-derived relaxing factor influences renal vascular resistance. Am J Physiol 259:F9-17

31. Elsner D, Muntze A, Kramer EP, Riegger GA 1992 Inhibition of synthesis of endothelium-derived nitric oxide in conscious dogs. Am J Hypertens 5:288291 
32. Bhardway R, Moore PK 1989 The effect of arginine and nitric oxide on resistance blood vessels of the perfused rat kidney. Br J Pharmacol 97:739_ 744

33. Fineman JR, Heymann MA, Soifer SJ $1991 \mathrm{~N}^{\omega}$-nitro-L-arginine attenuates endothelium-dependent pulmonary vasodilation in lambs. Am J Physiol 260:H1299-H1306

34. Bhardway R, Moore PK 1988 Endothelium-derived relaxing factor and the effects of acetylcholine and histamine on resistance blood vessel. $\mathrm{Br} \mathrm{J}$ Pharmacol 95:835-843

35. Adzick NS, Harrison MR, Flake AW, Laberge JM 1985 Development of a fetal renal function test using endogenous creatinine clearance. $J$ Pediatr Surg 20:602-607

36. Stonestreet BS, Bell EF, Oh W 1979 Validity of endogenous creatinine clearance in low birth-weight infants. Pediatr Res 13:1012-1014

37. Ercan ZS, Soydan AS, Turker RK 1990 Possible involvement of endothelium in the response of various vasoactive agents in rabbit isolated perfused kidney. Gen Pharmacol 21:205-209

38. Burton GA, MacNeil S, de Jonge A, Haylor J 1990 Cyclic GMP release and vasodilation induced by EDRF and atrial natriuretic factor in the isolated perfused kidney of the rat. Br J Pharmacol 99:364-368

39. Kon V, Harris RC, Ichikawa I $1990 \mathrm{~A}$ regulatory role for large vessels in organ circulation. Endothelial cells of the main renal artery modulate intrarenal hemodynamics in the rat. J Clin Invest 85:1728-1733

40. Baylis C, Harton P, Engels K 1990 Endothelial derived releasing factor controls renal hemodynamics in the normal rat kidney. J Am Soc Nephrol 1:875881

41. Tolins JP, Palmer RM, Moncada S, Raiji L 1990 Role of endothelium-derived relaxing factor in regulation of renal hemodynamic responses. Am J Physiol 258:H655-H662

42. Burton GA, Griffith TM, Edwards DH 1989 EDRF-mediated dilation in the rat isolated perfused kidney: a microangiographic study. Br J Pharmacol 98:1207-1212

43. Cassin S, Dawes GS, Mott JC, Ross BB, Strang LB 1964 The vascular resistance of the foetal and newly ventilated lungs of the lamb. J Physiol (Lond) 171:61-79

44. Tiktinsky MH, Cummings JJ, Morin FC 1992 Acetylcholine increases pulmonary blood flow in tact fetuses via endothelium-dependent vasodilation. Am J Physiol 262:H406-H410
45. Tod ML, Cassin S 1992 Endothelin-1-induced pulmonary arterial dilation is reduced by $\mathrm{N}^{\omega}$-nitro-L-arginine in fetal lambs. J Appl Physiol 72:1730-1734 46. Christie MI, Lewis MJ 1991 A comparison of endothelium-derived releasing factor activity in the coronary and renal arteries of the pig. Eur J Pharmacol 202:143-149

47. Shaul PW, Farrar MA, Zellers TM 1992 Oxygen modulates endotheliumderived relaxing factor production in fetal pulmonary arteries. Am J Physiol 262:H355-H364

48. Lieberthal W, Wolf EF, Remke HG, Valen CR, Levinsky NG 1989 Renal ischemia and reperfusion impair endothelium-dependent vascular relaxation. Am J Physiol 256:F894-F900

49. Perrella MA, Edell ES, Krowka MJ, Crotese DA, Burnett Jr JC 1992 Endothelium-derived relaxing factor in pulmonary and renal circulation during hypoxia. Am J Physiol 263:R45-R50

50. Hill KJ, Lumbers ER 1988 Renal function in adult and fetal sheep. J Dev Physiol 10:149-159

51. Zatz R, de Nucci G 1991 Effects of acute nitric oxide inhibition on rat glomerular microcirculation. Am J Physiol 261:F360-F363

52. Cairns HS, Rogerson ME, Westwick J, Neild GH 1991 Regional heterogeneity of endothelium-dependent vasodilation in the rabbit kidney. J Physiol (Lond) 436:421-429

53. Siragy HM, Johns RA, Peach MJ, Carey RM 1992 Nitric oxide alters renal function and guanosine $3^{\prime}, 5^{\prime}$-cyclic monophosphate. Hypertension 19:775779

54. Lumbers ER, Smith FG 1989 Measurement of net sodium intake by the ovine fetus with esophageal ligation. Clin Exp Pharmacol Physiol 16:859-866

55. Biondi ML, Bolterman RJ, Romero JC 1992 Zonal changes of guanidine 3',5'. cyclic monophosphate related to endothelium-derived relaxing factor in dog renal medulla. Renal Physiol Biochem 15:16-22

56. Perrella MA, Hildebrand FLJ, Margulies KB, Burnett Jr JC 1991 Endotheliumderived relaxing factor in regulation of basal cardiopulmonary and renal function. Am J Physiol 261:R323-R328

57. Salem MG, Lahera V, Romero JC 1991 Role of prostaglandins and endothelium-derived relaxing factor on the renal response to acetylcholine. Am J Physiol 260:F145-F149

58. Reyes AA, Martin D, Settle S, Klahr S 1992 EDRF role in renal function and blood pressure of normal rats and rats with obstructive uropathy. Kidney Int 41:403-413

59. Kim KM, Kogan BA, Massad CA 1992 Acute hemodynamic and endocrinological effects of partial fetal bladder obstruction. J Urol 148:497-502 